\title{
LAS TEORÍAS Y SU INFLUENCIA POLÍTICA Y SOCIO-JURÍDICA EN LOS PROBLEMAS DE LA DEMOCRACIA
}

Cuando en nuestro tiempo hablamos de teorías en contextos como el que ocupa este trabajo, a saber la democracia, los problemas de su gobernabilidad, sus crisis y sobre todo su involución actual, lo hacemos desde un determinado uso de la palabra «teorías». Pensamos en teorías científicas desde el campo de las ciencias sociales y políticas. Empero, dentro del carácter polivalente de la palabra «teorías» se suelen distinguir, en general dos significados: uno amplio, que abarca la totalidad de la doctrina de una corriente o de un pensador sobre un objeto, aquello que los alemanes designan como "die Lehre», regla, patrón, modelo, en que se incluye la descripción de los hechos, su explicación, los juicios de valor, los fines y las acciones que propone. Otro, más restringido, concebido como pensamiento explicativo si se trata de ciencias causales centradas en lo empírico y el razonamiento formal o, normativo, si se trata de disciplinas del deber centradas en el concepto de validez.

En Las Leyes de Platón una institución agrupaba a los teóricos o theorei, encargados de visitar el extranjero para observar los sistemas educativos y jurídicos de las otras ciudades. A su regreso el teórico, el theoro, debía exponer los resultados a las más altas autoridades de la ciudad. Hoy día podemos imaginarnos la influencia de estos expertos a partir de sus contactos con la más amplia gama de experiencia política y la valoración de lo que conocían. La mejor pista para ubicar esa influencia, surge del hecho de que los theorei eran portadores de Theoria, una palabra que -como se observa-, tenía en su raíz Theos, Dios, voluntad omnipotente y creadora. En cuanto a la filosofía, sinónima, como es conocido, de metafísica, connotaba la apasionada búsqueda de la sabiduría. Teología, filosofía y ciencia (theoria), estaban así entrelazadas en un principio básico: el de la unidad del saber.

Este principio acompañó largo tiempo el pensamiento de la antigüedad y el medioevo, hasta la modernidad, en que se produjo la ruptura y la separación de los tres polos, en un cambio revolucionario en el que la ciencia (theoria) y la filosofía se independizan de la teología, produciéndose los siguientes 
resultados. La religión no pudo ya dar las espaldas al pensamiento científico y, por otro lado, la mínima diferencia que separaba la ciencia de la filosofía se convirtió en una brecha profunda. Los theorei, pese a la carga teológica de su apellido, se hicieron laicos, seculares, sospechando $\mathrm{y}$ recelando de las especulaciones intelectuales, mientras que los filósofos consideraron sumamente estrechos los resultados de las ciencias particulares. En el paso de la antigüedad a la modernidad la imago-mundi de la religión se suplantó por la imago-mundi de la razón. Retornar a las fuentes religiosas para acreditar la certeza de las observaciones empíricas, la objetividad descriptiva y la confiabilidad de las predicciones, se hizo tarea inaceptable.

Las teorías científicas debieron renunciar a este recurso y extraer de su propios procedimientos metodológicos aquello que garantizara la objetividad, es decir, la adecuada correlación de ellas con el mundo de la naturaleza o de la sociedad, la neutralidad de sus juicios y el desarrollo progresivo lineal, causal, acumulativo. En el mundo de la burguesía, de las operaciones económicas y comerciales, todo lo relacionado con lo cuantitativo se convirtió en patrón aplicado a los más diversos campos, incluso las teorías científicas.

La filosofia, por su parte, no se resignó a su completa separación de la ciencia. Redefinió sus vínculos con ésta y pretendió sujetarla a su jurisdicción a fin de cumplir su papel de garante y sostén de ella por medio de una categoría fundamental, la de la Verdad. Para poder ofrecer el enlace y la conexión adecuada entre el sujeto cognoscente y el objeto conocido produjo las piezas más maestras de la modernidad: el cógito cartesiano, y el sujeto trascendental y constitutivo de la crítica kantiana.

Siglos más tarde el positivismo de Comte, de Durkheim y del Kelsen de la Reinetheorie, como el utilitarismo de Bentham, no se contentaron con asegurar la neutralidad de la ciencia respecto de la religión. Dieron un paso más adelante y quisieron proveer métodos que separaran también el conocimiento científico de la política y la economía, de la sociología y la psicología, de la moral, la estética y los valores. En nuestro siglo llegó la hora de la epistemología y la metodología, con la propuesta fisicalista vienesa de un método único modelado sobre la física que debía extenderse, según Moritz Schlick, Rudolf Carnap, Otto Neurath y otros, a todo lo que tuviera los documentos en regla para aspirar a llamarse ciencia, theoria. Esa hora, como la del pensamiento analítico oxfordiano, está hoy a fines de siglo declinante, en crisis.

Pero esta declinación, paradójicamente, no es signo de nada, no señala el triunfo de una corriente sino, más bien, se constituye en síntoma de otra cosa: la complejidad de los fenómenos, la perplejidad del rumbo que está tomando el mundo en manos de otros expertos, de una nueva raza de theorei, 
que se apropian de la teoría científica económica y social, y de una filosofía que llaman posmoderna, para justificar una democracia que no se hace gobernable sino se cobija perversamente en un gran paraguas que la preserve de la pobreza de los seres humanos, y la sistemática destrucción de los bienes naturales.

Veamos en un solo plano, el de los theorei en lo económico, cómo opera su influencia señalando pautas que traban la gobernabilidad de la democracia en cuanto justifican políticas para pocos, excluyentes de muchos.

2. Hace ya más de un siglo el conocido economista John Maynard Keynes puso fuerte acento en su obra General Theory (1936) en la fuerza política que tienen las teorías, las ideas y los discursos, y llamó la atención sobre la influencia de los theorei. Keynes se refiere a la teoría en general, alude a teóricos que generan teoría social y económica que domina en un momento dado, aunque nosotros nos pronunciaremos específicamente sobre el tipo particular de theorei que instalaron su dominio en nuestros días bajo consignas monetaristas. Como recuerda Wolfgang $\mathrm{Merkel}^{1}$, en este texto que inició una importante corriente del pensamiento económico hoy desplazado, Keynes advierte: «Las ideas de los economistas y de los filósofos políticos, ya estén en lo cierto o sean erróneas, son más poderosas de lo que es comúnmente admitido». Dos son, en general, las maneras en que se ejerce esta influencia: una, directa y concreta mediante juicios de expertos que influyen en las acciones políticas de los actores estatales; otra, mediante versiones más bien populares y difusas de teorías científicas y tesis filosóficas que encuentran aceptación en el conjunto de los ciudadanos. El acierto o el desacierto de estas teorías no está correlacionado puntualmente con sus resultados. Teorías e ideas desacertadas pueden tener buenos frutos políticos y, a la inversa, teorías e ideas correctas carecer de todo éxito. Cuando una teoría se hace dominante, marca fuertemente los juicios de una nación sobre el papel del Estado, la política, el derecho y otros aspectos de la vida social. Para indicar este fenómeno Antonio Gramsci elaboró su concepto de hegemonía cultural. Mientras que otra u otras teorías se mantienen en un papel débil, apartado, pero conservando siempre todas sus expectativas de cambio.

Claus Offe, en Contradicciones del Estado de Bienestar ${ }^{2}$, propuso un modelo dividido en tres escenarios para hacer comprensibles los efectos del discurso político. El primero es el del aparato estatal en que élites políticas

\footnotetext{
${ }^{1}$ Wofgang Merkel, Entre la modernidad y el postmaterialismo. La socialdemocracia europea a finales del siglo XX. Alianza, Barcelona, 1994.

${ }^{2}$ Clauss Offe, Contradictions of the Welfare State, Cambridge, 1984. En De la maldad estatal y la soberania popular, editorial Debate, Madrid 1984, Elías Díaz realiza un excelente estudio crítico de las ideas de este filósofo alemán.
} 
toman sus decisiones legislativas sobre el presupuesto y los programas de política social. En un segundo y menos accesible escenario, operan como actores colectivos grupos, asociaciones y corporaciones, que concurren y se ligan en un entramado de intereses para fijar, distribuir y controlar el acceso a los recursos sociales como los medios de producción y de comunicación. Para identificar a este escenario, Offe transforma la sigla más tradicional de factores de poder por la de «social power matrix», matriz del poder social. En el tercero, se fabrican cambios de tendencia del espíritu de la época, se tejen nuevas redes de crítica a la hegemonía de los theorei justificadores del sistema que, aconsejando las decisiones del primer escenario, dan todo su apoyo a las corporaciones del segundo, y abren las puertas para nuevas ideas e intereses.

¿Cómo operan los consejeros hegemónicos o theorei en la nueva coyuntura mundial? En lo básico, consideran que los valores fundamentales de la libertad, la justicia y la solidaridad social, deben quedar subordinados al crecimiento económico y la modernización de las relaciones sociales, traduciendo modernización por desestatalización, privatización y eficacia. Interpretan la inflación, la absorción del crédito por el Estado y la deuda pública como los únicos factores que conspiran contra la estabilidad. Con respecto a esta última incurren en una palpable y no inocente contradicción. Theorei de los países acreedores y de los países deudores, alientan en la década de los setenta la mayor expansión de un tipo particular de deuda, la llamada deuda externa. A la hora de acordar los créditos aconsejan ser flexibles y elásticos en la exigencia de requisitos para el acceso a los préstamos, y se desinteresan del análisis y control de las posibilidades reales de recupero. Una vez contraída la deuda, exigen que el Estado, al que acusan de estatitis, asuma la deuda privada, y se convierten luego en los críticos mayores de esa misma deuda pública, asumiendo el papel de implacables erinias en las propuestas a la burocracia administrativa de entes internacionales sobre los métodos compulsivos de cobro y las puniciones por falta de pago en término. En forma absolutamente no fortuita, la deuda se contrae en muchas oportunidades bajo dictaduras militares sin ningún control de las instituciones legítimas legales, y se debe abonar en pleno funcionamiento de los gobiernos democráticos. Pero los theorei se consideran «neutrales» respecto de los aspectos políticos esenciales que se juegan alrededor de sus opiniones y dictámenes.

Una creciente ofensiva de los theorei neoliberales se articula alrededor del concepto del «minimal state» de Nozick en el que, en forma directa o indirecta, se alinean propuestas como las de Dahrendorf, Crozier, Bell, Friedman, Hayek, Buchanan y otros, para quienes las reformas económicas deberían estar respaldadas, como así ocurre en los hechos, por las reformas jurídicoinstitucionales 
que liberen el intercambio de bienes de la intervención política. Herbert Giersch, vocero de la ciencia económica alemana define en este sentido la libertad del empresariado, como libertad negativa: libertad de todas las reglas y regulaciones que limitan la actividad empresarial.

Estas exigencias forman una red con aspectos que se ven reproducidos cotidianamente, descriptos por Merkel: a) en lo fiscal, renuncia a este instrumento como motor cíclico de desarrollo. Transferencia de la carga impositiva de los impuestos directos a los indirectos; limitación y reducción, en los planes de ajuste del gasto público. b) prioridad de la política monetaria como arma contra la inflación. e) extensa privatización de industrias y servicios de sectores competitivos. d) política social. Derogación de las prestaciones sociales paralela a la privatización de riesgos como paro, enfermedades, jubilaciones y pensiones. Reducción drástica del gasto público social. e) mercado de trabajo. Desregulación del mercado, flexibilidad laboral en materia de jornada laboral, vacaciones, normas de seguridad y salud en el puesto de trabajo.

Tales transformaciones regresivas económicas reclaman el correlato correspondiente de los cambios legislativos, las normas y la hermenéutica administrativa y judicial, en la que los theorei económicos, llamémoslos de primer grado, requieren contar con el complemento de otros theorei jurídicos de segundo grado, influyentes en su respectivo nivel.

3. En este tramo, corresponde pasar de los aspectos económico-sociales que venimos considerando, a las respuestas que puede dar la teoría jurídica sobre la influencia de ella en la gobernabilidad de la democracia. Existen dos corrientes, el positivismo y el utilitarismo que, con alto grado de probabilidad, habrán de desalentar una toma de posición en esta cuestión u otras semejantes.

El positivismo en la medida que reduce la teoría a los hechos y considera que la ciencia es acumulativa en tanto empírica. Jeffrey C. Alexander en «La centralidad de los clásicos» ${ }^{3}$ sostiene que el positivismo en ciencias sociales se basa en cuatro postulados fundamentales: 1) Existe una ruptura epistemológica radical entre las observaciones empíricas, que se consideran específicas y concretas, y las proposiciones no empíricas que se consideran generales y abstractas. 2) A partir de 1), se afirma que las cuestiones más generales y abstractas, filosóficas o metafísicas, no tienen importancia para la práctica de una disciplina de orientación empírica. 3) Las cuestiones de índole general, abstracta y teorética, sólo pueden ser formuladas proposicionalmente y evaluadas empíricamente. Los conflictos teóricos deben ser

\footnotetext{
${ }^{3}$ Incluido en La teoría social hoy de Anthony Giddens y otros. Alianza Editorial, Barcelona, 1990.
} 
evacuados a través de las contrastaciones empíricas y los experimentos cruciales. 4) El desarrollo científico es lineal y acumulativo.

Estos postulados implican la instalación del laissez faire, laissez passer, le monde va de lui même económico clásico, en el universo de lo jurídico y convierten al positivismo, por renuncia al análisis, en "compañero de ruta» del thacherismo y la reaganomic más radical, confiando -manera indirecta de aceptar- en las fuerzas espontáneas de la economía, y en la benevolencia de acreedores e inversores. Secundariamente, y por las mismas razones de neutralidad, sus recetas toman distancia de otro tipo de propuestas planteadas desde una nueva izquierda por teóricos de la regulación, como Aietta, Lipietz y Boyer ${ }^{4}$, que no discutiremos aquí.

Tanto el monto de pobreza, privación y pérdida de derechos en el mundo de la salud, la cultura y la alimentación provocado por las doctrinas de los theorei económicos, como el monto de control de inflación y ajuste que estas doctrinas sostienen resolver, son cuestiones empíricas y medibles. Pero no entran en los cálculos postulados por el positivismo. En realidad, el positivismo dice tener en su portafolios experimentos cruciales y contrastaciones empíricas para decidir los conflictos teóricos, pero estas decisiones nunca se han adoptado en su historia, pese a la enorme masa de leyes y normas jurídicas que descienden sobre esta problemática.

Lo que ocurre es que la metodología positivista de los experimentos y las contrastaciones empíricas es completamente insuficiente e inadecuada para resolver cuestiones teóricas de este tipo, aunque ambos polos sean empíricos, sino se parte de evaluaciones, valores, creencias e incluso ideologías relativas al mundo de la sociedad. Exactamente lo mismo ocurre si las contrastaciones debieran realizarse entre las eventuales ventajas de una política de mercado y de primacía absoluta del mundo de los negocios, frente a las consecuencias destructivas del mundo de la naturaleza. Los polos empíricos aislados del debate esterilizan la solución teórica, si ésta no se interpreta explicando las preferencias conforme a una clasificación comparativa de valores, de evaluación de resultados y probabilidades cualitativos y no meramente cuantitativos.

Decir que una teoría es verdadera tomando solamente en cuenta parte de sus implicaciones empíricas (ajuste, equilibrio o supuesto equilibrio del

\footnotetext{
${ }^{4}$ Estos teóricos intentan reconstruir lo histórico y estructural, conforme a una lógica de cambios internos, viendo funcionar el sistema como un todo de formas y estructuras en conjunción con mecanismos económicos asociados. Pero se apartan del concepto marxista de totalidad sustituyendo el concepto de reproducción por el de regulación. De estos theorei pueden verse: Michel Aglietta, Regulations et crises du capitalisme. París 1976. «World Capitalism in the Eighties». New Left Review (126) 1982. Alain Lipietz, en la misma revista (132), 1982 «Towards Global Fordism» y Robert Boyer, Theorie de la Regulation, Bilan, Critique, Perspectives, París, 1976.
} 
mercado) y desestimando las otras, precisamente las más graves, no sirve para respaldar esa teoría.

Desde un punto de vista estrictamente filosófico, Donald Davidson ha explicado cómo toda teoría de la decisión tiene que apoyarse en una teoría de la interpretación (que llama radical), que tenga en cuenta las creencias, las intenciones y los valores ${ }^{5}$.

Es cierto que existen formas remozadas de positivismo que rehabilitan los aspectos teóricos, especialmente en trabajos de Lakatos, Polanyi y Holton, pero este neopositivismo está más relacionado con ciencias duras, y no ha tenido repercusión en lo jurídico. Como, por ejemplo, cuando este último autor observa que el enfrentamiento entre compromisos teóricos generales es el más poderoso catalizador de investigaciones empíricas y componente esencial de las transformaciones fundamentales de las ciencias naturales ${ }^{6}$.

En cuanto al utilitarismo sigue, en esto, las mismas aguas del positivismo. Recordemos, meramente, 1) la concepción liberal de «estado mínimo» de Jeremy Bentham, aunque no es semejante a la del anarquismo conservador de Nozick. 2) su proyecto de un felicific calculus, método de medición aritmética y cuantitativa de la variedad y la intensidad del placer y el dolor. 3) respecto del problema de la pobreza, su creencia de que ante el fracaso de las workhouses, su modelo de cárcel, el Panóptico, podía proporcionar la panacea para dos ramas a las que veía casi como parientes: the prisioner branch and the pauper branch. Presentando este Panóptico, junto con su hermano Samuel, como una alternativa o sucedáneo para la fracasada Poorlaw Bill de Pitt $^{7}$.

\footnotetext{
${ }^{5}$ Véase al respecto su libro De la verdad y de la interpretación. Gedisa. Barcelona, 1990, que incluye en particular sus artículos «La interpretación radical» y «La creencia y el fundamento del significado». Asimismo su conferencia inédita sobre la interpretación pronunciada en el Centro Descartes de psicoanálisis. Buenos Aires, agosto de 1994.

${ }^{6}$ Gerald Holton. Thematic Origins of Scientific Thought: Kepler to Einstein. Cambridge, Mass. Harvard University Press. En 1911, Mach junto con otros signatarios como Einstein, Petzoldt, Hilbert, Klein, Helm y Freud, redactaron un manifiesto en favor de la creación de una sociedad para la difusión de la filosofía positivista. En su artículo «Où est la réalité? Les reponses d'Einstein», incluido en Science el synthèse, Gallimard, París. 1967. Holton examina las posteriores diferencias entre Einstein y Mach. A la ciencia descriptiva y económica de Mach, Einstein oponía en un segundo período una ciencia creadora e intuicionista. En una carta del 24 de enero de 1938, a su amigo C. Lanezos, escribe: «Yo venía del empirismo escéptico, un poco del género que profesaba Mach. El problema de la gravitación me transformó en racionalista convencido, es decir, en un hombre que busca la única fuente valiosa de verdad en la simplicidad matemática. Sin duda, lo que es lógicamente simple no es necesariamente físicamente verdadero, pero lo que es físicamente verdadero es lógicamente simple, es; decir, que hay unidad en su base».

${ }^{7}$ Acerca de esta cuestión se puede consultar de Enrique E. Marí, La problemática del castigo. El discurso de Jeremy Bentham y Michel Foucault. Hachette, Buenos Aires, 1983 y de Darío Melossi y Massinio Pavarini, Cárcel y Fábrica. México, Siglo XXI, 1980.
} 
4. Frente a este estado de la teoría económico-social actual y la falta de respuestas en corrientes examinadas de la teoría jurídica, en nuestra opinión otras corrientes deben ocupar el espacio del tercer escenario de Offe. Es decir, deben preparar los cambios de la «social power matrix», fabricando opuestas tendencias a este espíritu de la época, estructurando nuevas redes de crítica a la hegemonía de los theorei justificadores del sistema y abriendo las puertas para nuevas ideas. En una palabra. deben incrementar las expectativas de cambio, remover los obstáculos a la gobernabilidad de la democracia y defender los intereses legítimos de los desplazados, su libertad e igualdad social.

La tarea no es fácil. El derecho es básicamente conservador en dos sentidos, uno objetivo y otro en las posiciones de la academia y muchos de los juristas. Es «objetivamente» conservador porque parte de un axioma fundamental, el de la prohibición, que tiene prioridad epistemológica sobre el principio de permisión. La prohibición es un principio originario. Tiene todo el carácter de un término primitivo en el sentido de la lógica. Opera en forma metasistemática como cobertura social de todo el ordenamiento.

Ningún sistema es concebible compuesto por la totalidad de acciones permitidas. El principio de que «Todo lo que no está prohibido está permitido» resguarda la lógica de al menos un último deseo imposible de satisfacer jurídicamente. El principio se puede enunciar de otra manera: «En el sistema jurídico todo está prohibido o permitido». Pero esta fórmula es engañosa pues no fija cuál de los dos conceptos es el primitivo. De cualquier modo no se puede enunciar nunca como «Todo está prohibido», o «Todo está permitido», en proposiciones autónomas no conectadas por una conectiva vel.

En «El postulado jurídico de la prohibición», incluido en Ideas para una filosofía del derecho, Tomo I, Buenos Aires ${ }^{8}$, Ambrosio Gioja observa que aun cuando desde un punto de vista puramente lógico-formal cualquiera de las dos expresiones pudieran tomarse como primitivos, «en sus relaciones con el orden jurídico-positivo se descubre que «prohibido» es el concepto

${ }^{8}$ Ideas para una filosofía del derecho, texto compilado por Ricardo Entelman, incluye el artículo «El postulado jurídico de la prohibición» de Ambrosio Gioja. T. I. Librería Jurídica Abeledo. Buenos Aires, 1973, editado por Sucesión Ambrosio L. Gioja.

Sobre el Principio de la prohibición se expiden también, entre otros juristas, Georg H. von Wright en «An Essay in Deontic Logic and the General Theory of Action», Acta Philosophica Fennica XXI, Helsinki y en Norma $y$ Acción, Tecnos Madrid, 1970. Hans Kelsen en La Teoría Pura del Derecho, Eudeba, Buenos Aires, $4^{\mathrm{a}}$ edición, 1965, y en Teoría General del Estado y el Derecho. UNAM. México, 1969. Alf Ross. Lógica de las Normas. Tecnos, Madrid, 1971. C. Alchurrón y E. Bulygin, Introducción a la metodología de las ciencias jurídicas. Astrea, Buenos Aires. Nino Carlos Santiago, Introducción al análisis del Derecho. Astrea, Buenos Aires. 
básico. Por consiguiente corresponde una definición de éste a fin de hacer inteligible todo el sistema».

La existencia de la coacción, como nota básica del derecho constituye para la mayor parte de los autores el pendant del Principio de la prohibición. Al explicar la noción de satisfacibilidad Georg Henrik von Wright llama la atención sobre esta asimetría lógica, en «Normas de orden superior», de esta manera: «Diré que una norma que prescribe que un cierto estado de cosas es obligatorio es satisfacible si, y sólo si, es (lógicamente) posible que este estado de cosas se dé en todas las ocasiones durante la historia de esa norma. Una norma que prescribe que un cierto estado de cosas está permitido es, a su vez, satisfacible si, y sólo sí, es posible que este estado de cosas se dé en alguna ocasión durante la historia de la norma»?

El postulado de la plenitud hermética del derecho señala un ideal de completitud que gira alrededor de un eje primordial; la prohibición de al menos una acción. Gioja dice en su trabajo: «Claro que puede haber sociedad y no existir, por ejemplo, normas jurídicas o religiosas. Pero insistimos, la desaparición de normas de este tipo implicaría la desaparición de la sociedad». Hans Kelsen, por su parte, en Teoría General del Derecho y del Estado afirma que la palabra derecho es expresión de un concepto con un significado social altamente importante en toda época y lugar. «Pues la palabra se refiere a esta técnica social específica de un orden coactivo que, pese a las grandes diferencias entre el derecho de la Babilonia antigua y el de los Estados Unidos en la actualidad o entre el de los Ashanti en África occidental y el de Suiza en Europa, es, sin embargo, esencialmente el mismo para todos estos pueblos tan diversos desde el punto de vista del tiempo, del lugar y de la cultura, a saber: la técnica social que consiste en provocar la conducta socialmente deseada a través de la amenaza de una medida coercitiva que debe aplicarse en caso de un comportamiento contrario. Cuestión sociológica muy importante es la que estriba en saber cuáles son las condiciones sociales que hacen necesaria esta técnica. Ignoro si podemos contestar satisfactoriamente esta pregunta. Tampoco sé si es posible a la humanidad emanciparse totalmente de esta técnica social. Pero si el orden social no hubiere ya de tener en el futuro el carácter de un orden coactivo y la sociedad pudiera existir sin «derecho», entonces la diferencia entre la sociedad del futuro y la de nuestra época sería inconmensurablemente mayor que la que hay entre los Estados Unidos y la Babilonia antigua o entre Suiza y la tribu de los Ashanti».

La condición de la existencia de la sociedad depende, en rigor, de la no desaparición de al menos una norma prohibitiva. Un deseo, como ocurre

\footnotetext{
${ }^{9}$ «Normas de orden superior» de Georg Henrik von Wright, incluido en El Lenguaje del Derecho. Homenaje a Genaro R. Carrió, op. col. Abeledo-Perrot, Buenos Aires, 1983.
} 
exactamente en la problemática del psicoanálisis, tiene que estar mínimamente interdicto. Conocemos ese deseo, en este último caso: el incesto. La prohibición del incesto tratada por Freud en Totem y Tabú y otras obras, revela que para el tránsito del mundo de la pura naturaleza al mundo de la cultura, tiene que existir un deseo imposible de cumplir, un deseo que por su imposibilidad de ser satisfecho recibe el nombre de deseo-carencia. Así como este deseo-carencia es condición de la subjetividad humana, condición de constitución del sujeto, la prohibición de al menos un deseo transportado en acción es condición social de constitución del sujeto jurídico. Situación que fija una importante vía de acceso a la comparación entre derecho y psicoanálisis.

Esto significa que en, uno y otro caso, nos encontramos con un juego de dados cargados o de naipes en que el mazo está completo pero un carta, por función dogmática, no es sana para la partida. El derecho es, en efecto, un curioso juego de naipes marcados en el que el as de triunfo de la permisiblidad total, la libertad absoluta, vaciaría a los hombres de sociedad y cultura. En el derecho no hay as de triunfo, así como no lo hay en la tópica de la sexualidad con el incesto prohibido. En ambos, nadie quiere jugar con una ventaja-límite porque se perdería con la mejor carta. No hay aquí carta blanca para «todo». Sorprendentes juegos en donde de lo que se huye es de las martingalas y de las jugarretas. En los que no es bueno meter las narices en las cartas del otro, ya que el inconsciente y la pervivencia social, desbordando la razón, actúan como gran vigilante, como control del Gran Otro. Irresoluble juego de dados cargados en el que no se puede arrojar el cubilete para que éstos caigan en cualquiera de las caras.

Con la prohibición del incesto se instala una forma de comercio sexual determinado, donde no impera en su totalidad la fisiología, que impulsa a los animales ir más allá de toda barrera. Una red simbólica instalada in illo tempore, el tiempo mítico e impreciso de la organización de la sociedad, controla la fisiología, la circunda mediante el recurso de la prohibición del incesto. Una cama, está interdicta, una cópula desbaratada, una historia de amor no tiene alcance, ni éxito, ni término. El Eros Alpinista, del que nos hablaba Platón en el Symposium tiene que elegir forzosamente otras cumbres. Si Midas tiene amores plurales, de esa pluralidad hay que retirar una opción más peligrosa que el oro. El amor incestuoso de Fedra por Hipólito no hace ley porque viola la Ley. Sólo el cegado de Edipo por Yocasta tiene el privilegio de constituir esta Ley. Ya sabemos a qué precio.

En el amor acuático de Narciso, su mirada tiene que quedarse pegada a sí mismo en la superficie del lago. No le es dado ir más allá, más profundo hacia la ninfa azul, Liríope, su madre, violada por el dios fluvial. A menos que deseara afrontar la predicción de Tiresias, monotemático de adivinanzas: 
«Narciso vivirá hasta la edad madura con tal que nunca se conozca a sí mismo».

El código de la relación de placer él-el otro, él-su madre, exige la ruptura de este segundo término a una edad de la niñez para que en el pre-sujeto psíquico se estructuren en forma cohesiva inteligencia, cuerpo, lenguaje. Del mismo modo el código de la relación social exige que un deseo no pueda llevarse a la acción, que una acción esté jurídicamente prohibida para que los pre-sujetos jurídicos pueblen como sujetos la sociedad.

Por todo ello, cualquier teoría que pretenda instalarse en el tercer escenario de Claus Offe debe tener presente que no puede existir como mera articulación de metodología pura, e incorporar la política, la sociología y las reglas de constitución de la subjetividad psicológica, sino se quiere ingresar en este juego de naipes objetivamente marcados o de dados cargados esterilizando su crítica.

Permítaseme ahora dar término a este trabajo con la siguiente observación. La influencia de las teorías en el espacio público, tanto las neoconservadoras como las críticas es, como fuera observado, relevante. Pero no necesariamente el tercer escenario de Offe tiene que ser monopolizado por teorías cognoscitivas. El mismo puede ser repoblado también por observaciones, ideas, y críticas que se generan en la literatura, el arte y otros segmentos de la cultura.

Nada mejor para comprobarlo que recurrir a la obra incompleta de Robert Musil, uno de los más brillantes escritores austríacos, cuyo texto El hombre sin atributos es un paradigma de cómo la ironía literaria, ese género intermedio entre la frialdad y el sentimiento como lo definiera Maurice Blanchot, puede denunciar personajes, actitudes del gobierno y la administración que, aunque relativos al Imperio Austro-Húngaro, resulta aplicable a la ciudad, costumbres y actitudes de nuestra época. Hablamos de sus descripciones del Reino de Kakania.

\section{ROBERT MUSIL Y EL HOMBRE SIN ATRIBUTOS DEL REINO DE KAKANIA}

1. A comienzos de nuestro siglo Viena se constituyó en el epicentro de un asombroso movimiento cultural irradiado a los diversos países que integraban el Imperio Austro-Húngaro y a otras regiones del mundo. Como ya tuve ocasión de expresarlo, hablar de Viena en esos tiempos es hablar, junto a Casullo, a Janik y a Toulmin, de los tiempos alegres y despreocupados de los valses y las operetas de Strauss a orillas del Danubio Azul. Es evocar las horas doradas de «la belle epoque». Añorar las charlas en los cafés, los paseos en el Prater y en el Wiener Wald. Es recordar las fiestas imperiales en los Palacios de Invierno, de Belvedere y de Schönbrunn, con las chispeantes 
burbujas de los brindis de champán. Escritores, artistas, filósofos, científicos, contribuyeron a este brillo originado en distintas esferas: la dramaturgia de Hugo von Hofmansthal y Stefan Zweig, la música de Gustavo Mahler, la arquitectura de Loos, la psiquiatría de Schönberg, el austro-marxismo de Adler y Otto Bauer. La ciencia médica de Skoda, el Círculo de Viena de Carnap y Neurath, el empirismo de Mach con la dura réplica del Lenin, el materialismo y empirio-criticismo, dirigido básicamente a su discípulo Bogdanov. Las obras de Popper, Wittgenstein y Freud. La cáustica ironía en La antorcha del monstruo del periodismo vienés Karl Kraus («Ante todo debemos a menudo reflexionar de qué nos alegramos; pero se sabe siempre qué nos entristece»). Es, también, tener presente a Robert Roth el pasajero de Transeuropa Express, bebedor católico y autor de Judios errantes, no menos que a Elías Canetti.

Este grupo de intelectuales, entre los cuales Robert Musil, el autor de El hombre sin atributos, ocupó un segmento relevante, debió luego emigrar, en su mayor parte, con el asesinato del canciller Dolfuss y la anexión de Austria por Hitler, sin dejar de imprimir fuertes huellas al pensamiento de nuestro tiempo. Vale la pena desglosar, precisamente, parte de la obra de Robert Musil, quien pobló sus libros con un universo de imágenes y palabras que se disolvían como las dunas en el desierto, ya que lo que en realidad se deshacía era el cenit de una ciudad y un Imperio, el de Francisco-José, incluso desde algunos años antes del nazismo.

2. El hombre sin atributos es una novel a-recipiente de sátiras y denuncias sobre la crisis de Kakania, una palabra que menciona el Imperio de las Dos Coronas, en la que se funden kaiserlich-königlich, Imperial-Real, pero que tiene en su sentido y, al menos en nuestro idioma, (ka.ka: ka\&ka) una cacofonía acústica con un aroma de muy bajo perfil que ninguna muralla logró circunscribir, y que se extendió en el tiempo y en el espacio hasta el presente. Sólo su lenguaje pudo lograr que tanto los hombres que perdieron sus cualidades, como aquellos a los que nos dejaron sin ellas, tuviéramos la sensación física y la ilusión espiritual de respirar otros aires, como maravilla de su estética, su denuncia su sátira.

El título del libro le fue inspirado a Musil en su época de estudiante de ciencias físicas, y en la ocasión en que redactara su tesis en la Universidad de Berlín denominada «Para una evaluación de las doctrinas de Mach». Musil seguía las ideas del profesor de ciencias inductivas de Viena, sostenedor de la tesis básica antisustancialista de que los cuerpos, las cosas, la materia no son nada fuera de los atributos. Es decir, fuera del conjunto de sus elementos, los colores, los sonidos, el calor la presión y el tiempo, combinados en variadísimas formas y a los que se ligan los estados de ánimo, los sentimientos, las voliciones. Der Mann ohne Eigenschaften se inspira en las 
ideas de Mach, tanto en la descripción de sus personajes, Ulrich, Arnheim, Moosgruber, Clarisse, Agata y otros, como en el contexto de decadencia en que se involucran.

De familia aristocrática, y cadete de un colegio militar cuya forma de vida criticará en Las perplejidades del estudiante Törless, Musil girará luego a su verdadera vocación literaria, se convierte en otro emigrado del nazismo y muere en precaria situación económica. El hombre sin atributos le lleva cuarenta años de trabajo; la obra quedó inconclusa y no obtuvo el reconocimiento que esperara.

El Reino de Kakania es un imperio hundido no por los ciudadanos inmorales sino, especialmente, por los morales, en el que un hiperindividualismo no había sido capaz de producir un solo individuo. En él, un austríaco no era un simple austríaco sino un ciudadano de la Monarquía Dual compuesta por austríacos y húngaros, pero que sólo se acreditaba como ciudadano auténtico luego de una curiosa operación de «un austríaco más un húngaro menos ese húngaro».

En este Reino, del que Musil se había ocupado antes en «Política en Austria» y en sus Diarios, se mezclaban la frivolidad y la pasión, pero en las pasiones eran indiferentes los cuadros del afecto o el desafecto, del amor o el odio. La pasión no era otra cosa que un pretexto. La gente hace dinero con la política, y en el grupo que lo hace «se cierran respectivamente los oídos uno a otro». Los valores se juegan en el plano de la hipocresía. La religiosidad no es creíble, ni la infantil adhesión de los ciudadanos al Emperador, ni sus ansiedades; detrás de esto esperan siempre algo. La política no tiene fines o propósitos humanos, sino sólo austríacos. Cuando un huracán barre con los Ministerios, los Ministros caen como diestros gimnastas, pero cuando se calma la tormenta sus sucesores se repiten en las mismas posiciones, con cambios menores que los expertos aseguran ser satisfactorios, pero que quedan incomprensibles para el resto.

El instrumento de la democracia no es sólido, está plagado de contradicciones. Una capa singular, adquiere significativa influencia, peso político y social: los peluqueros. Mientras realizan su trabajo, peinando a las damas aristocráticas, frecuentan sus medios, sus tazas de té, y emiten sus opiniones sobre la política, y los demás aspectos de la vida social, curioso aspecto que se implanta emulando nuestra propia experiencia.

La antítesis económica propietario/proletario es sólo una excusa, una cortina de humo en el camino del mercado.

Musil no se limita a desnudar a la aristocracia y reserva la misma dureza para la burguesía. Precondición real de la cultura, ésta no cumple con su papel a causa de sus intereses comerciales. Está en mejor condiciones que la élite por no crear familias que declinan rápidamente, no apegarse a la tradición, 
a ideales heredados, ni a una dura moral. Pero aprende cosas en el período en que tiene que aprender a caminar, y las olvida cuando interfieren en su ruta. Carece de grandeza, de prototipos, de gente fascinante y, por el contrario, pone aparte a la gente creativa. Frente a sus intereses propios, el largo espectro de la conciencia está habitualmente ausente. En el capítulo 8 de su libro, que lleva el nombre de Kakania, Musil se imagina una Big City, que exhibe todos los defectos que hoy nos tocan vivir. Veámoslos.

El aire y la tierra forman una morada, un habitáculo, atestado con canales de tráfico que lo atraviesan como venas y pisos que se acumulan sobre pisos. Trenes subterráneos, correos neumáticos, cadenas de vehículos a motor verticales y horizontales que transportan multitudes humanas. «En los puntos de conexión se brinca de un medio de transporte al otro, sorbido y arrebatado por el ritmo que hace una pausa, una síncopa, un pequeño intervalo de veinte segundos entre dos rugientes explosiones de velocidad, y en estos intervalos en el ritmo general se cambian pocas palabras con otros». Entre estas palabras se intercambian preguntas y respuestas, pero ellas se exhiben como los dientes de una rueda. Cuando comes, comes en movimiento. A lo que, por nuestro lado, podríamos agregar: cuando tomas un café lo haces en taza de plástico para que la arrojes rápido al cesto, no pierdas tiempo y vuelvas al ritmo, al tiempo, a la velocidad, al movimiento.

Las diversiones están concentradas en sitios inéditos de la ciudad. En el shopping. El shopping listo para saltar con sus uñas y monopolizarlo todo. Para qué ir al café si lo tienes «a plástico» en el shopping. Para qué ir al cine, si lo tienes allí, listo para que a la salida te cruces rápido al café «a plástico» y no pierdas tiempo. Para qué ir a las diversiones si las tienes a un ojo, permitiendo que el otro mire los precios de las mercaderías que te incitan a comprar. Hazlo rápido, café, cine, diversión y compras, para cumplir con tu ritmo y puedas dejar taza, asiento y stand a otro que ocupe tu lugar en el espacio en que entregas tus cualidades, tus atributos.

Musil añora el retorno al punto anterior al camino equivocado. A la Austria de los viejos y buenos días en que se podía abandonar el tren de los eventos y tomar el tren normal, en una línea de ferrocarril normal y viajar de regreso a casa. Al tiempo donde no existía la ambición de poder y de mercados mundiales. A aquel en que existía lujuria pero no tan sofisticada como la francesa. Aquel en que se hacía sport pero no tan enloquecido como el de los ingleses. Aquel en que no se gastaban tremendas sumas de presupuesto reservado en el ejército, sólo para permanecer como segundos entre los más débiles de los grandes poderes.

En Kakania todos los ciudadanos eran iguales, pero, por supuesto, no todos eran ciudadanos. Había un Parlamento que hacía vigoroso uso de su libertad, 
pero que era habitualmente cerrado. Lo habitual era manejarse con superpoderes y decretos de emergencia.

El vicio básico de Kakania, digamos por fin, es descrito por Musil así: en Kakania se actuaba de un modo diferente del que se pensaba, o se pensaba de un modo diferente del que se actuaba. Los ciudadanos eran conscientes de los inadecuados fundamentos de su existencia. A ésta la cubría la fantasía de que nada había ocurrido o, al menos, de que nada había ocurrido irrevocablemente, «a la manera de la espuma de los océanos de la que surge la humanidad».

Una frase estaba en boca de todos: iEs ist passiert!, mientras que en otros lugares se decía que el cielo sabía «exactamente» lo que había pasado. Frase peculiar, sin equivalente en otros idiomas, algo como «¡Así son las cosas!», para disimular y no incluir en la memoria cómo las cosas habían sido realmente.

Lo que Musil no podía sospechar es que muchos años después, en un remoto país del Sur se usara, en medios oficiales, otra frase con más grado de cinismo: «los argentinos somos derechos y humanos», que aunque distinta en su expresión lingüística, tendría la misma función: encubrir, disimular los hechos, transformar «los cascotazos del destino», un destino promovido y desatado, en algo suave como una pluma.

Esto desde luego forma parte de otra historia, la historia de nuestros propios hombres sin atributos, sin cualidades, narrable en un capítulo que, en última instancia, nunca se podría cerrar a la manera en que Musil lo hace con su capítulo sobre Kakania: "A despecho de lo mucho que parece apuntar hacia la otra vía, Kakania fue, después de todo, un hogar para genios: y esto probablemente fue su ruina». 
DOXA 20 (1997) 